\title{
Investigation of the HelioVital filter foil revealed protective effects against UVA1 irradiation-induced DNA damage and against UVA1-induced expression of matrixmetalloproteinases (MMP) MMP1, MMP2, MMP3 and MMP15
}

\author{
I. Ivanova ${ }^{1}$ (1) B. Kurz ${ }^{1} \cdot \mathrm{K}_{\text {. } \text { Lang }^{2} \cdot \text { T. Maisch }^{1} \cdot \text { M. Berneburg }}{ }^{1} \cdot$ Y. Kamenisch $^{1}$
}

Received: 14 December 2021 / Accepted: 21 January 2022 / Published online: 16 February 2022

(c) The Author(s) 2022

\begin{abstract}
The damaging effects of solar ultraviolet (UV) radiation exposure to human skin are well known and can reach from accelerated skin aging (photoaging) to skin cancer. Much of the damaging effects of solar UVA (320-400 nm) radiation is associated with the induction of reactive oxygen species (ROS), which are capable to cause oxidative damage to DNA like the oxidized guanosine 8-hydroxy-2' -deoxyguanosine (8-OHdG). Therefore, new UV protective strategies, have to be tested for their efficiency to shield against UV induced damage. We investigated the protective effects of HelioVital sun protection filter foil against UVA1 irradiation in skin cells. It could be shown, that HelioVital sun protection filter foil has protective effects against UVA1 irradiation induced changes in matrix metalloproteinase (MMP) expression. Furthermore a UVA1-dependant regulation of MMP15 in human fibroblasts could be shown for the first time in this context. In addition, this study demonstrated the protective effect of the HelioVital filter film against UVA1-induced ROS production and DNA damage. These results could pave the way for clinical studies with HelioVital filter foil shielding against the damaging effects of phototherapy and other forms of irradiation therapy, thereby increasing the safety and treatment opportunities of these forms of therapy.
\end{abstract}

\section{Graphical abstract}

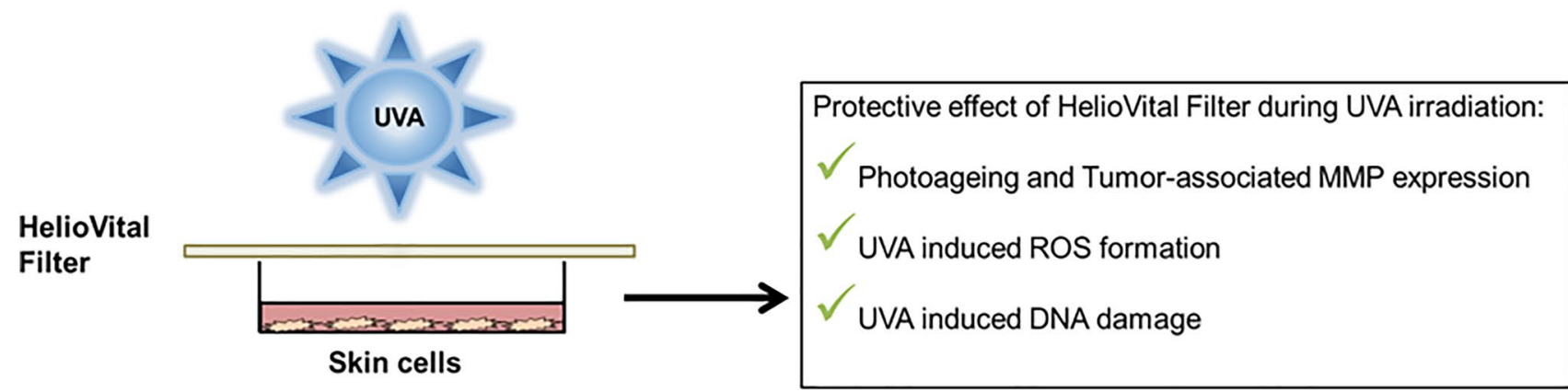

Keywords Ultraviolet (UV) radiation $\cdot$ UVA1 $\cdot$ HelioVital filter foil $\cdot$ Reactive oxygen species $\cdot$ MMP

I. Ivanova

Irina.Ivanova@ukr.de

Y. Kamenisch

York.Kamenisch@ukr.de

1 Department of Dermatology, University Hospital

Regensburg, 93042 Regensburg, Germany

2 HelioVital GmbH, Zollernring 32, 72186 Empfingen, Germany

\section{Abbreviations}

ROS Reactive oxygen species

MMP Matrix metalloproteinase

UV Ultraviolet 


\section{Introduction}

Most of the solar UV radiation reaching the surface of the earth consists of UVA (320-400 nm, subdivided in UVA2 (320-340 $\mathrm{nm}$ ) and UVA1 (340-400 nm) [1]) radiation (approximately 95\%) and only approximately $5 \%$ of UVB (280-320 $\mathrm{nm}$ ) radiation [2]. The UVA exposure of healthy people, considering the presence and quantity of UVA radiation in everyday life [2], can have negative effects on the skin at the cellular level. Compared to UVB, which can inflict direct damage by photon-mediated excitation of DNA and subsequent generation of pyrimidine dimers, UVA can damage cellular structures indirectly via the generation of reactive oxygen species (ROS) [3]. UVAinduced ROS can cause oxidative damage to DNA like 8-hydroxy-2' -deoxyguanosine (8-OHdG) [4], DNA double-strand breaks [5], and mediate lipid and protein oxidation [6-8]. Furthermore, UVA can penetrate much deeper into the skin compared to UVB, increasing the amount of affected tissue [9]. The plethora of cellular damage caused by UVA can translate to macroscopic skin malformations such as accelerated skin aging (photoaging) [10] and skin cancer, like squamous cell carcinoma (SCC), basal cell carcinoma (BCC) and melanoma [11], with continuously increasing prevalence and high mortality $[12,13]$.

Prominent markers of UVA-induced damage in the skin are matrix metalloproteinases (MMP). The UVAinduced expression of matrix metalloproteinases, especially MMP1, MMP2, and MMP3, is an important feature in the process of UV-induced skin aging, especially in photoaging [14]. These proteases degrade proteins of the extracellular matrix in the skin and promote the formation of wrinkles in photoaged skin. In addition to this, MMP1 and MMP2 are important players during carcinogenesis of melanoma and many other tumors [14]. These proteases can be secreted by the tumor stroma [15] or the cancer cells themselves and help initial melanoma cells to invade the extracellular matrix, which is an important prerequisite for metastasis and vascularization of tumors [16-18]. Furthermore, high expression of MMP15 has been associated with the progression of SCC [14].

Despite its role in skin cancer formation and photoaging, solar and artificial UV radiation has a continuously increasing spectrum of clinical applications [19] as part of artificial light therapy [20] and heliotherapy in form of outdoor sun exposure. As part of artificial light therapy, both broad-band UVA and long-wave UVA1 are implemented for the treatment of pruritus, prurigo, atopic dermatitis, polymorphous light eruption, and cancer (in the form of photochemotherapy (PUVA)) [20]. Exposure to natural sunlight can have effects on the treatment of mood disorders, atopic dermatitis and psoriasis [21-23].
However, as already mentioned, the damaging effects of UVA irradiation and their long-term consequences, which can develop years after exposure, are a major drawback to its clinical application [24-27].

A field that can greatly benefit from improved protection strategies against UVA-induced damage is the Photodynamic Therapy (PDT), a treatment usually prescribed in cases of actinic keratosis (AK), Bowen disease, and certain types of basal cell carcinoma [28, 29]. The classical application of PDT requires specialized devices and trained medical personnel [30]. In recent years, Daylight-Mediated Photodynamic Therapy (daylight PDT) has been proposed as an alternative to classical PDT. Daylight PDT substitutes specialized therapeutic devices with a regulated outdoor sun exposure, resulting in greater benefits for the patients in form of lower cost, flexibility, and reduced stress and pain [31]. Daylight PDT-treatment proved effective against AK, independent of weather conditions. Even irradiation reduction by $83 \%$ due to cloud-cover resulted in successful treatment as long as a minimal irradiation dose of $3.5-8 \mathrm{~J} / \mathrm{cm}^{2}$ was achieved [31, 32]. However, patients have reported increased pain load when treatment was performed on a sunny day, with the lowest pain-score recorded on rainy or cloudy days [31]. Furthermore, there are indications that cloudy weather conditions do not always correspond to reduction of solar irradiance. Depending on cloud formation and composition, it is possible to receive higher irradiation doses when the weather is cloudy compared to clear-sky conditions [33], which can be detrimental for the patients.

Despite recent advancement in UV-protection technology and materials [34-36], alternative means for UVA protection are still in high demand. New protective strategies have to be tested for their efficiency to shield against UV-induced damage without reducing its therapeutic potential.

In this work, we investigated in skin cells the protective effects of HelioVital filter foil against UVA1 irradiation. In detail, the protective effects of HelioVital filter foil against UVA1-induced changes in cell viability, expression of matrix metalloproteinases (MMP), reactive oxygen species (ROS), DNA damage (measured with comet assays) and UVA1-specific DNA damage (8-OHdG) were investigated. The results showed that UVA1 irradiation-induced DNA damage, MMP expression and ROS production can be ameliorated by HelioVital filter foil. An additional outcome of this study was the discovery of UVA1 regulation of MMP15-a metalloproteinase, which was not reported to have UV-dependent modulation in human fibroblasts [14]. 


\section{Results}

\subsection{Protective effect of HelioVital filter foil against UVA1 induced changes in cell viability}

In initial experiments, primary human skin fibroblasts were irradiated with sub-lethal doses of UVA1 for 4 consecutive days (spectral profile of the lamp and irradiation protocol are presented in Supplementary Fig. 1 and 2, respectively). The irradiation was conducted with and without protection by HelioVital filter (Fig. 1b), a filter foil which can absorb approximately $60 \%$ of solar UV radiation (Transmission of UVB-25.3\%, UVA2-40.3\%, UVA1-41.9\%, see Fig. 1a and Supplementary Fig. 3). Repetitive UVA1 irradiation did not decrease cell viability (Fig. 2a). However, the significant decrease in the overall amount of viable cells points to UVA1-induced proliferation retardation (Fig. 2b). This observation was confirmed when the doubling times of the UVA1-treated and untreated cells were compared (Fig. 2c). The application of HelioVital filter foil ameliorated this UVA1-induced effect on proliferation (Fig. 2b, c), which might be due to less UVA1-induced DNA damage occurring in HelioVital filter foil protected skin cells.

\subsection{Protective effect of HelioVital filter foil against UVA1-induced reactive oxygen species (ROS)}

The UVA-induced ROS are an important mutagen, which can cause severe cellular damage [37]. To investigate the protective effect of HelioVital filter foil against UVA1 induced ROS, primary human skin fibroblasts were

a

Transmission of HelioVital Filter Foil - Type LTL-3-130om

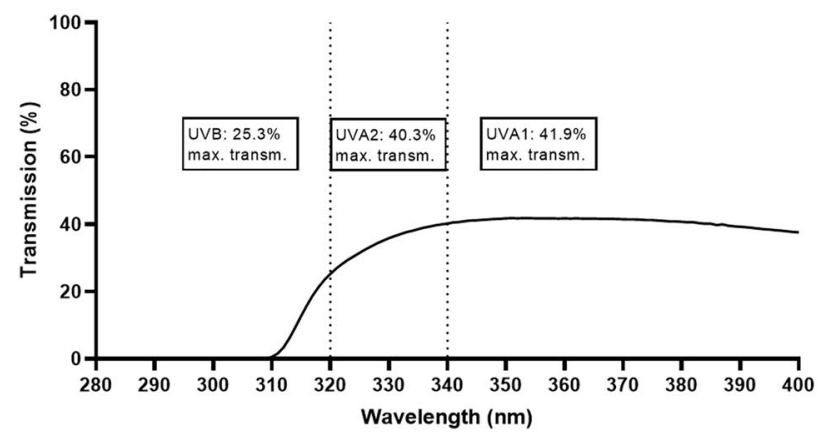

Fig. 1 a Transmission of HelioVital filter foil in the range 280$400 \mathrm{~nm}$. The filter shows a reduction in transmission for both UVB $(280-320 \mathrm{~nm})$ and UVA $(320-400 \mathrm{~nm})$ radiation by $60 \%$. b Schematic representation of the HelioVital Filter Foil composition foil and irradiated as described in the material and methods section with subsequent detection of ROS levels. To improve detection of ROS, a single dose of $18 \mathrm{~J} / \mathrm{cm}^{2}$ UVA1 was used. This single dose of $18 \mathrm{~J} / \mathrm{cm}^{2}$ is better suited than repetitive low-dose UVA1 treatment for ROS detection with our ROS detection system. When primary human skin fibroblasts are treated with UVA1 irradiation, the ROS level is increased in these cells. This effect can be decreased when skin cells are protected by a HelioVital filter foil during irradiation (Fig. 3a, b).

\subsection{Protective effect of HelioVital filter foil against UVA1-induced DNA damage}

It is well known that UVA -induced ROS can cause oxidative damage to DNA like 8-OHdG. However, UVA damage is not limited to oxidative lesions, there are many additional types of DNA damage induced by UVA irradiation, such as single or double strand breaks [38]. To detect these damages, comet assays were performed (Fig. 4a-c). In these assays, the damage is measured by the length of comet tails and the tail moment as described in the materials and methods section.

To investigate the protective effect of HelioVital filter foil against UVA1-induced DNA damage, primary human skin fibroblasts were irradiated with sub-lethal doses of UVA1, as described in the material and methods section and comet assay was performed to detect DNA damage. Repetitive UVA1 irradiation increased the tail moments (Fig. 4a) and tail length (Fig. 4b), which can be reduced by protection with HelioVital filter foil during UVA1 irradiation.

b

Schematic representation of HelioVital Filter Foil layers

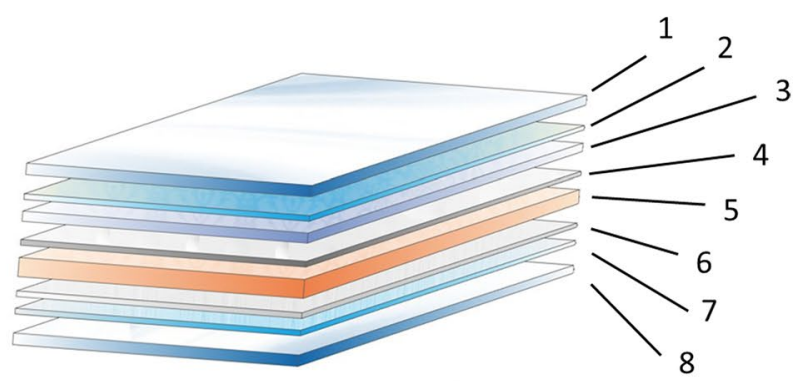

its functional layers. $(1,8)$ Protective and weary layer, $(2,7)$ Adhesive layer, (3) Print layer, (4) Metallization layer, (5) Filter layer, (6) Pigmentation layer 

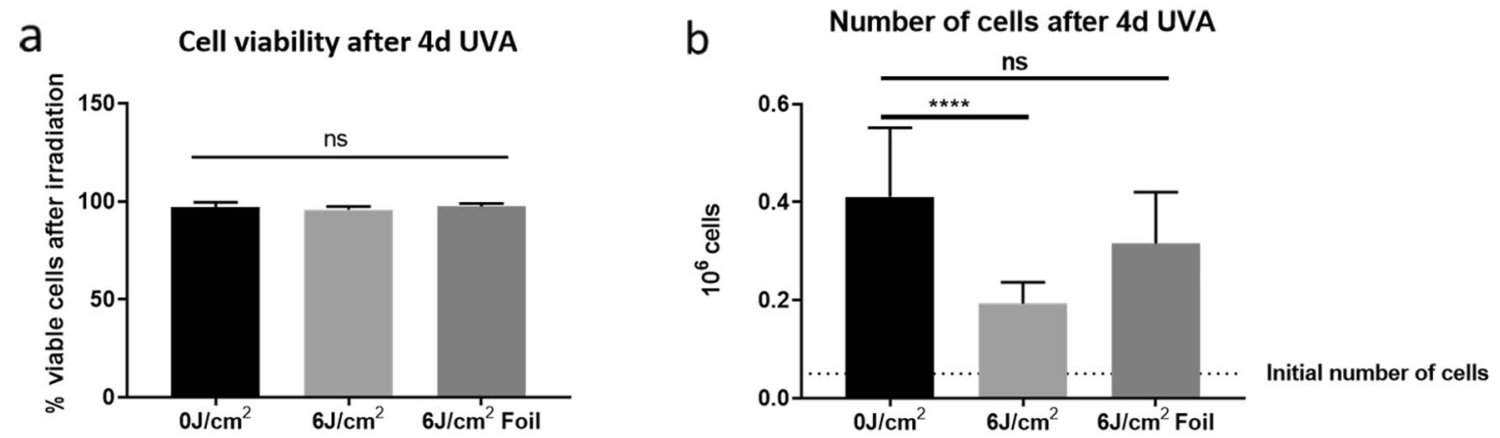

C Doubling times measured after 4d UVA

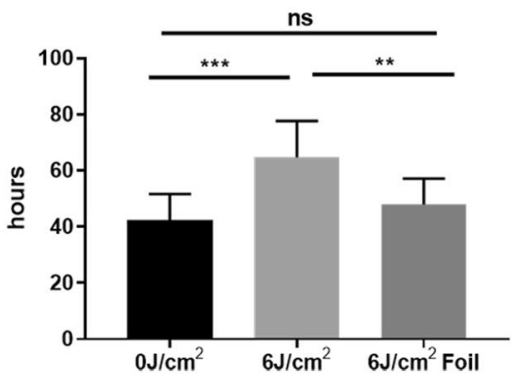

Fig. 2 a The repetitive irradiation of primary human fibroblasts with UVA1 $\left(3 \times 6 \mathrm{~J} / \mathrm{cm}^{2}\right.$ per day for 4 days, see Irradiation protocol 1 in Supplementary Fig. 2) has no significant influence on their viability. For this measurement, the number of total cells counted at the end of total treatment (4 days UVA1) was compared to the number of live cells detected in the cell suspension and the percent viable cells was derived. b The number of primary human fibroblasts is significantly decreased upon UVA1 treatment (4 days of UVA1 irradiation) and this effect can be ameliorated through protection with HelioVital sun protection foil. Since there is no change in the overall viability between treatments (a), differences in the end number of cells are indicative of reduced proliferation rather than apoptosis. c In primary human fibroblasts, 4 days of UVA1 irradiation lead to increase in doubling time. The HelioVital sun protection foil can significantly reduce UVA1-induced changes in cell proliferation. (ANOVA with Bonferroni's multiple comparisons test. (ns) $P>0.05$; (**) $P<0.005$; (***) $P<0.0005 ;(* * * *) P<0.0001)$

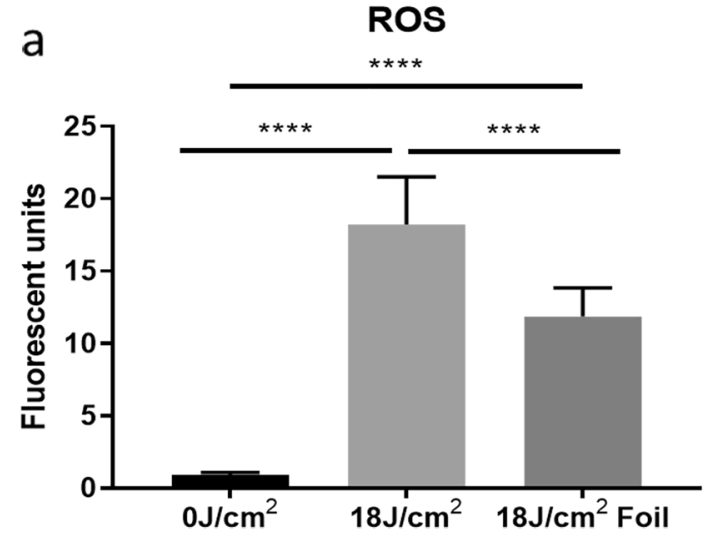

Fig. 3 a Protection of ROS formation by HelioVital filter foil. In primary human fibroblasts UVA1 treatment induced ROS formation can be reduced when cells are protected with HelioVital filter b Cellviability after $1 \times 18 \mathrm{~J} / \mathrm{cm}^{2}$ UVA

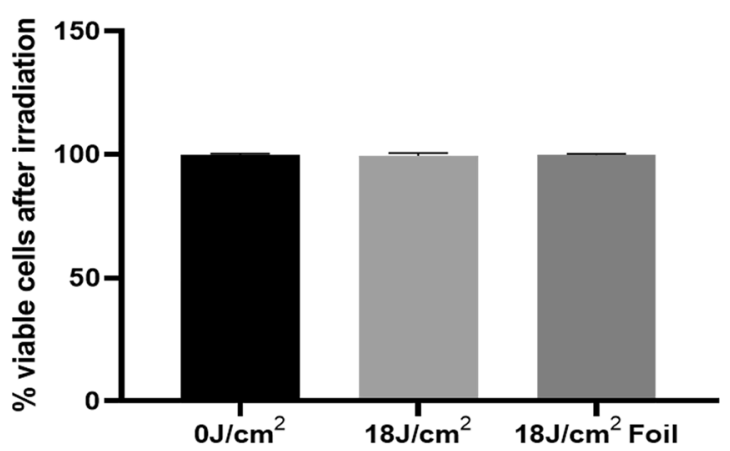

foil (ANOVA with Bonferroni's multiple comparisons test. (****) $P<0.0001)$. b Despite increased irradiation dose, there was no change in cell viability during the ROS-detection experiment

The UVA1-induced formation of the DNA base modification $8-\mathrm{OHdG}$ is associated with photoaging and carcinogenesis. To investigate the protective effect of HelioVital filter 
a $\operatorname{Re} 5$ 4d UVA Comet assay: Tail moments

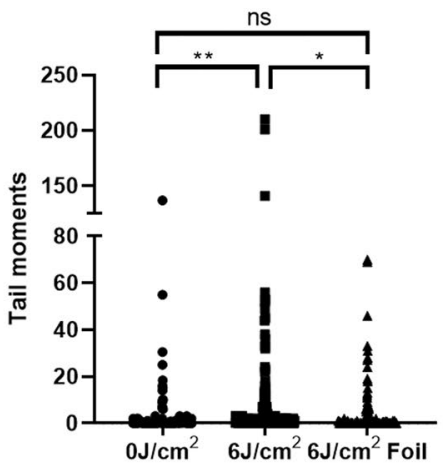

b Re5 4d UVA Comet assay: Tail lenghts

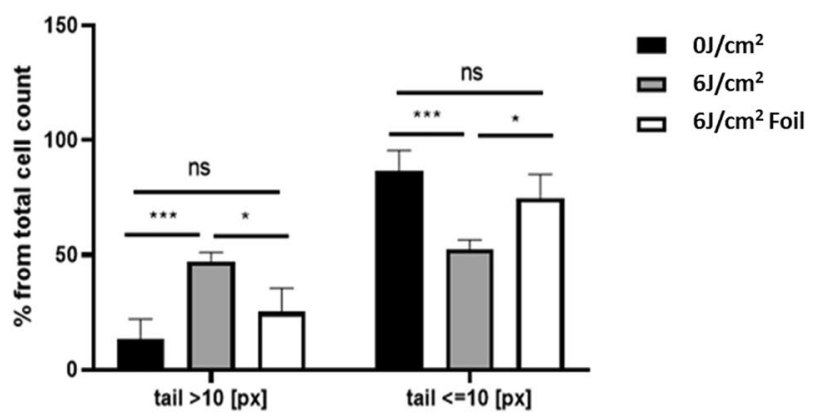

C

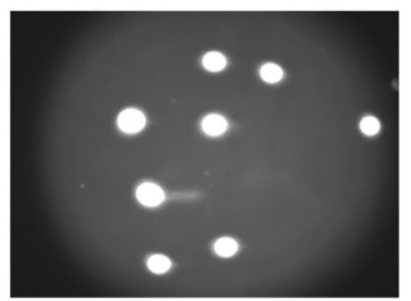

$0 \mathrm{~J} / \mathrm{cm}^{2}$

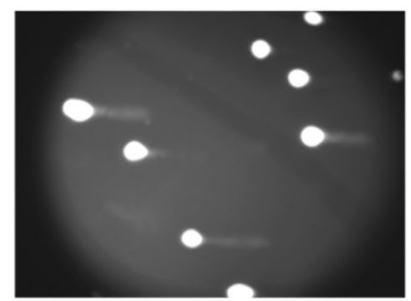

$6 \mathrm{~J} / \mathrm{cm}^{2}$

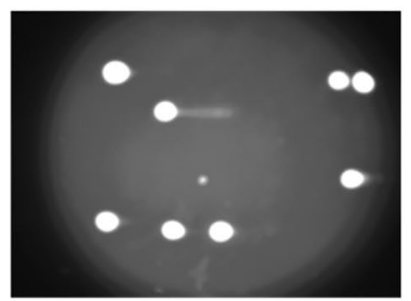

$6 \mathrm{~J} / \mathrm{cm}^{2}$ Foil
Fig. 4 HelioVital filter significantly reduces the overall tail moment (a) and the formation of large comet tails (tail length $>10 \mathrm{px}$ ) (b) after 4 days of UVA1 irradiation of primary adult human fibroblasts. A minimum of 50 cells were analysed per condition for each biologi-

foil against UVA1-induced DNA damage 8-OHdG, primary human skin fibroblasts were irradiated with sub-lethal doses of UVA1 as described in the material and methods section with subsequent detection of 8-OHdG levels. The 8-OHdG measurements were performed after 2 days UVA1-treatment since preliminary data (Supplementary Fig. 4) have shown that after 4 days irradiation the levels of $8-\mathrm{OHdG}$ reach a plateau and no significant differences between irradiated and non-irradiated cells can be observed with the detection technology used.

Repetitive UVA1 irradiation increased the $8-\mathrm{OHdG}$ level in human fibroblasts compared to untreated controls. Application of HelioVital filter foil during UVA1 irradiation showed a tendency of 8-OHdG reduction (Fig. 5) compared to the level of UVA treatment. However, the difference in the 8-OHdG levels between UVA-treated cells with and without foil were not statistically significant.

\subsection{HelioVital filter foil ameliorates UVA1 effects on the expression of matrix metalloproteinases (MMPs)}

To investigate the protective effect of HelioVital filter foil against UVA1-induced expression of matrix metalloproteinases and tissue inhibitor of matrixmetalloproteinases cal replicate $(n=3)$. (ANOVA; $P<0.01$, Bonferroni's multiple comparisons test. Whiskers represent min. to max. values. (ns) $P>0.05$; (*) $P<0.05$; (**) $P<0.005$; (***) $P<0.0005$ ). c Three representative images used for the comer-evaluation. $p x$ pixel

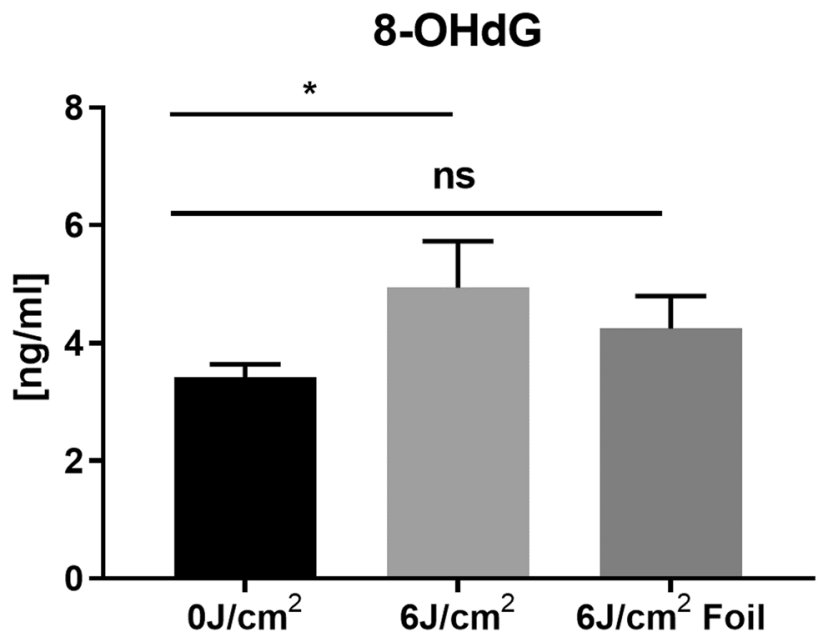

Fig. 5 In primary human fibroblasts, UVA1 irradiation induces formation of 8-OHdG. The amount of DNA damage can be reduced when cells are protected with HelioVital filter foil to levels similar to the untreated control (ANOVA with Bonferroni's multiple comparisons test. (ns) $P>0.05$; (*) $P<0.05$ )

(TIMP1), primary human skin fibroblasts were irradiated with sub-lethal doses of UVA1 for 4 consecutive days with and without protection by HelioVital filter foil. 
Subsequently, the expression levels of matrixmetalloproteinases (MMP1; MMP2; MMP3; MMP9; MMP13; MMP15) and TIMP1 were measured.

When primary human skin fibroblasts are irradiated, the expression of MMP2 (Fig. 6b), MMP3 (Fig. 6c), and MMP15 (Fig. 6d) is significantly increased in these cells compared to untreated controls. This effect can be reduced when skin cells are protected by a HelioVital filter foil during irradiation (Fig. 6a-d). The attenuation of UVA-induced MMP3 expression levels by the filter foil was not significant, but expression of MMP3 in UVA-irradiated filter foil protected cells was similar to the levels seen in untreated control cells with no statistically significant difference between these two levels (Fig. 6c).

Together with the filter-dependent attenuation of UVAinduced expression of MMP1, MMP2, MMP3 and MMP15, UVA induced TIMP1 expression also decreased after applying HelioVital filter foil (Fig. 6e). This could be explained as a coordinated effect of the treated cells. As there are less
MMPs present in samples irradiated with HelioVital filter foil, less TIMP1 is needed.

Not all the investigated matrixmetalloproteinases are significantly influenced by UVA1 irradiation or filter foil protection (Supplementary Fig. 5). This could be explained by a low expression level of MMP9 and MMP13 in these cells.

Taken together our results show that UVA1 induced an elevated expression of MMP2 and MMP15 and this effect can be ameliorated by HelioVital filter foil during UVA1 irradiation.

\section{Discussion}

It is well known that UVA irradiation can damage cellular structures and can induce photoaging and carcinogenesis $[10,39,40]$. In this work, we have shown that the HelioVital filter foil has the capacity to reduce UVA-induced cellular damage.
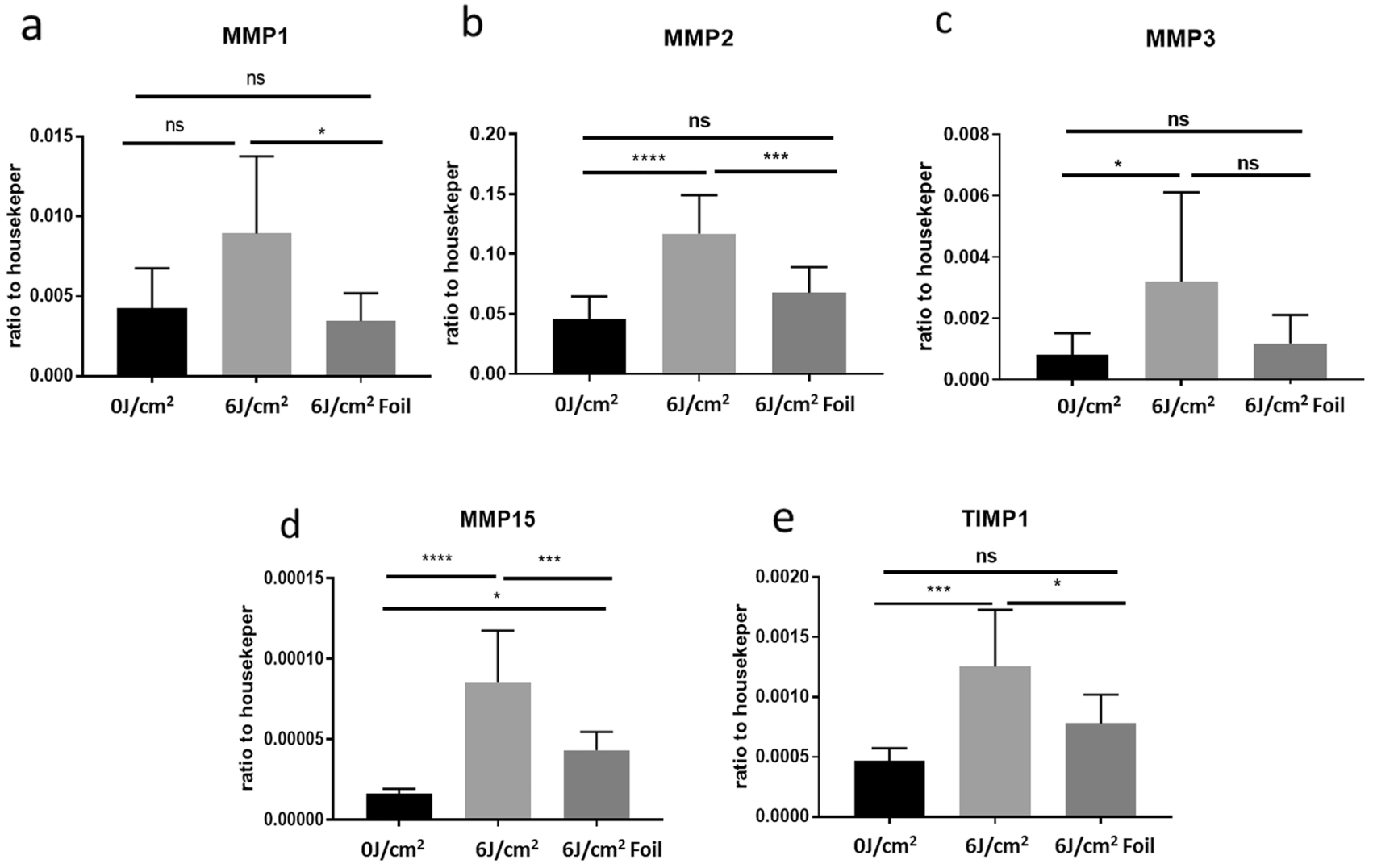

Fig. 6 Primary human skin fibroblasts were irradiated with sub-lethal doses of UVA1 for 4 consecutive days with and without protection by HelioVital filter foil. Relative to expression of housekeeper (b-Actin), UVA1 increases the expression of MMP1 (a), MMP2 (b), MMP3 (c), MMP15 (d), and TIMP1 (e). With the exception of MMP1, the UVA-induced expression changes are significant in all other MMPs and TIMP1. The application of HelioVital Filter foil reduces, UVAdependent, the gene expression significantly in the case of MMP1

(a), MMP2 (b), MMP15 (d), and TIMP1 (d), compared to samples irradiated without protection. MMP3 (c) shows a tendency (albeit not significant) of decreased gene expression in samples protected by HelioVital filter foil compared to UVA-treated unprotected samples. HelioVital-protected MMP3 expression levels are similar to the ones of un-irradiated samples. (Statistical analysis: ANOVA with Bonferroni's multiple comparisons test. (ns) $P>0.05$; (*) $P<0.05$; (**) $P<0.005 ;(* * *) P<0.0005 ;(* * * *) P<0.0001)$ 
In regard to UVA1-induced oxidative damage, cells irradiated without the protection of the HelioVital filter had significantly increased ROS production compared to both untreated controls and cells irradiated with filter. The amount of reactive molecules that could potentially damage cellular components was significantly reduced when foil was applied compared to unprotected irradiation. Furthermore, the alkaline comet assay showed significant decrease in both tail moments as well as tail length in cells irradiated in the presence of HelioVital filter compared to un-filtered irradiation (Fig. 4a, b). In addition to that, a tendency of reduction in oxidative DNA-damage marker 8-OHdG was observed in cells protected by HelioVital filter foil (Fig. 5). Even though the reduction of ROS formation and DNA damage did not reach the level of untreated control cells, the data presented in this work show that the application of HelioVital filter ameliorates UVA1-induced damage.

Besides reducing the damaging effects of UVA1 on DNAlevel, the application of HelioVital filter resulted in significant reduction of MMP1, MMP2, MMP15, and TIMP1 expression compared to cells irradiated without foil protection. No significant changes in the expression of MMP3 could be observed between cells irradiated with and without foil, although the application of HelioVital filter resulted in reduction of expression to levels similar to the ones observed in un-irradiated controls. This data imply that the application of HelioVital filter could be beneficial for the reduction of photoaging and skin cancer-associated MMP expression.

In the context of MMP regulation, it is important to note that, as far as we know from literature, there have been no reports of MMP15 being UVA1-regulated in human fibroblasts. This work is the first describing such UVA-dependent modulation of expression in this type of non-malignant cells [14]. Such behavior of MMP15, however, is not surprising since Gendron et al. have reported of UVA-dependent MMP15 expression in aged human cornea [41]. In their work on UVA and melanoma, Kamenisch et al. have observed increased lactate secretion after UVA-irradiation and lactatedependent regulation of multiple MMPs, including MMP1, MMP2, and MMP15, and TIMP1. If this UVA-dependent metabolic change would be similar in dermal primary fibroblasts, it would be possible that the increased expression of MMP15 observed in the current work has a similar UVrelated metabolic regulation.

However, the TIMP1 upregulation after UVA radiation observed in the current work was unexpected. Up to now, studies have shown either no influence of UVA radiation on TIMP1 expression levels $[42,43]$ or even a decrease expression [44]. However, our experimental setup was different from the ones described in these studies [42-44]. In the case of Herrmann et al., the used dose was a single $180 \mathrm{~kJ} / \mathrm{m}^{2}$ $\left(18 \mathrm{~J} / \mathrm{cm}^{2}\right)$ [42] while in our experiment, the cells were irradiated repeatedly with $60 \mathrm{~kJ} / \mathrm{m}^{2}\left(6 \mathrm{~J} / \mathrm{cm}^{2}\right)$ three times per day for 4 days, yielding a cumulative dose of $720 \mathrm{~kJ} / \mathrm{m}^{2}(72 \mathrm{~J} /$ $\mathrm{cm}^{2}$ ). In the study by Catalgol et al., a decrease of TIMP1expression levels was observed $3 \mathrm{~h}$ after UVA radiation. [44], whereas in our experiments, the cells were incubated over night before mRNA collection was done to determine TIMP1 expression levels. Since it is known that MMPs and TIMPs have a temporal regulation [45], and since the cells used are healthy wild-type fibroblasts, it could expected that there is an upregulation of TIMP1 as an antagonist of MMPs to preserve "tissue homeostasis". In contrast, Naru et al. concluded that TIMP1 shows no UVA-dependent changes in expression, despite showing UVA-regulation of TIMP1 in "older" cultured cells at maximum irradiation dose of $20 \mathrm{~J} /$ $\mathrm{cm}^{2}$ [43]. However, the UVA radiation dose used by Naru et al. correlates closely to the cumulative $18 \mathrm{~J} / \mathrm{cm}^{2}$ daily dose used in our study and the cells used were obtained from an adult donor (compared to the fibroblasts used by Naru et al. [43]). Therefore, we believe that the findings described by Naru et al. do not contradict the data from our study.

In addition to its protective function, since there is only a partial block of the UVA1 irradiation by HelioVital foil (see Fig. 1a and Supplementary Fig. 3), it is possible to use the residual $40 \%$ transmittance of radiation in diverse therapeutic applications such as daylight PDT.

An effective daylight PDT requires at least $3.5-8 \mathrm{~J} / \mathrm{cm}^{2}$ of solar irradiation, a dose-range achieved even under weather conditions when up to $83 \%$ of irradiation is blocked by cloud cover [31, 32]. Since the HelioVital filter foil absorbs approximately $60 \%$ of solar UV irradiation (Fig. 1), which is in a range mimicking cloudy or partially cloudy weather conditions [31-33], it could be applied as sun-shielding during daylight PDT, giving the patients the benefit of reduced pain load even on sunny days [31]. Furthermore, the application of a HelioVital filter on sunny days could provide the benefits of reduced radiation exposure of cloudy weather without the variable cloud formation.

In addition to the potential benefits of HelioVital filter foil for patients undergoing PDT, another aspect of interest could be its application in the field of hormetic therapies. For some years, the hypothesis of hormesis has attracted attention. It suggests that a small dose of stressors could be beneficial for the organism by improving long lasting defense strategies against these stressors [46, 47]. This hypothesis was already tested for ROS and it was found that continuous small doses of ROS could activate antioxidant defense systems [46-48]. Since ROS are induced by UVA and are one major damaging effect of this type of irradiation, it can be assumed that small doses of UVA could also have beneficial hormetic effects. The newly developed HelioVital filter foil, can shield approximately $60 \%$ of the solar UV irradiation, but can pass a limited amount of UVA irradiation (Fig. 1 and Supplementary Fig. 3). From the perspective of the hormesis theory, the resulting small amounts of oxidative 
damage to cells could be important stimulators to maintain antioxidative protection, like the expression of proteins of the antioxidative defense system [46, 49-51]. These possible applications of the HelioVital filter foil open the path for new UV protective strategies, which do not completely block, but attenuate the intensity of UV radiation.

\section{Conclusion}

We could show that UVA1-induced damage to skin cells can be ameliorated by HelioVital sun protection filter foil. Furthermore, we could show for the first time UVA1-dependant regulation of MMP15 in human fibroblasts. HelioVital sun protection filter foil had protective effects against UVA1 irradiation-induced changes in cell proliferation and MMP expression and against UVA1 irradiation-induced ROS production and DNA damage. These results pave the way for clinical studies with HelioVital filter foil shielding against the damaging effects of phototherapy and other forms of irradiation therapy, thereby increasing the safety of these treatments. Furthermore, protection with HelioVital filter foil could increase the number of applications of these therapies and could contribute to achieve a balance between potential beneficial effects and damaging effects of UVA1 exposure.

As basis for later applications of these HelioVital filter foil as sun protection or as filter in artificial light therapy and heliotherapy, more in vitro safety studies with low doses of repetitive UVA1 treatment have to be performed.

\section{Materials and methods}

\subsection{Isolation and culturing of human fibroblasts}

Skin biopsy samples of healthy volunteers were obtained from the University Hospital Regensburg (Ethic vote number 14101 0001). The whole skin biopsy was put on a Primaria cell culture dish (Corning, USA), containing a single drop of DMEM-Cipro (DMEM $1 \mathrm{~g} / \mathrm{L}$ glucose (Gibco, Thermo Fisher) supplemented with 10\% FCS (Fetal + High Performance Serum, anprotec), 1\% Penicillin/Streptomycin (Sigma-Aldrich), 1\% Ciprofloxacin (Fresenius Kabi)), and incubated for $30 \mathrm{~min}$ at $37^{\circ} \mathrm{C}$ to ensure that the skin sample sticks on the dish surface. Afterward, $3 \mathrm{ml}$ DMEM-Cipro were added to the skin sample. It was cultivated at $37{ }^{\circ} \mathrm{C}$, $5 \% \mathrm{CO}_{2}$ until cell-outgrowth of fibroblasts was enough for a transfer to a T25 cell culture flask. Subsequently, the cells were transferred to a T75 flask, cultured in DMEM without Ciprofloxacin, and used for further experiments under the designation Re5.

\subsection{Irradiation protocols for skin cells}

The irradiation of $\operatorname{Re} 5$ fibroblasts was performed as follows. Cells were seeded at $5 \times 10^{4}$ cells per well on a 6 -well plate and left to grow over night before the start of UVA1-treatment. The standard irradiation protocol is shown schematically (Supplementary Fig. 2), and described in detail below. It had the duration of 4 days, with $3 \times 6 \mathrm{~J} / \mathrm{cm}^{2}$ per day. All irradiations contained three test groups $-0 \mathrm{~J} / \mathrm{cm}^{2}, 6 \mathrm{~J} / \mathrm{cm}^{2}$ and $6 \mathrm{~J} / \mathrm{cm}^{2}+$ Filter foil. After the fourth day of irradiation and overnight incubation, the cells were counted, viability was determined, and the cells were collected for further analysis. mRNA and DNA was isolated for qPCR analysis and 8-OHdG measurement, respectively (Data for 8-OHdG after 4 days of UVA1 irradiation are shown in Supplementary Fig. 4). Additional data for $8-\mathrm{OHdG}$ were collected after 2 days of UVA1 irradiation. A complete protocol of the 8-OHdG measurement can be found in Sect. 5.6.

At the beginning of irradiation, the medium was aspired form each well. Cells were irradiated in $1 \mathrm{ml}$ PBS. The amount of UVA1 per single irradiation was set at $6 \mathrm{~J} / \mathrm{cm}^{2}$ and provided by a Sellamed 1200 Lamp [Sellas Medizinische Geräte $\mathrm{GmbH}$, Germany) with an emission spectrum 340-420 nm (see Supplementary Fig. 1)]. The PBS was then aspired and $5 \mathrm{ml}$ fresh medium were added to each well after the first irradiation. Before all subsequent irradiations the medium was aspired and collected in separate falcons and returned to the corresponding wells after wards. Three irradiations per day were performed. There was $4 \mathrm{~h}$ resting period between single irradiations with $\mathrm{ON}$ rest after the last daily irradiation. The duration of total irradiation was 4 days. Before the first irradiation of day $3,1 \mathrm{ml}$ fresh medium was added to each well to compensate for medium loss. The HelioVital Filter LTL-3-130om (PP-PET-met.-multilayerfilm) was added between UVA1 lamp and cells in one of the experimental groups. After overnight incubation, cells were collected for RNA extraction.

A separate irradiation protocol of a single irradiation $\left(1 \times 18 \mathrm{~J} / \mathrm{cm}^{2}\right)$ was performed for the purpose of ROS detection. A graphic representation of the treatment can be found in Supplementary Fig. 2 and the complete procedure of ROS detection can be found in Sect. 5.5.

\subsection{Two-in-one cell count and viability test}

To determine the number of cells, as well as their viability, a LUNA-FL Dual Fluorescence Cell Counter (Logos Biosystems, Inc., South Korea) in combination with Acridine orange/Propidium iodide (AO/PI) staining (BioCat) was used. Acridine orange (AO) and propidium iodide (PI) are nucleic acid binding dyes. AO can permeate both live and dead cells and intercalates with DNA, generating green fluorescence. PI can only enter dead cells who have poor 
membrane integrity. It then generates red fluorescence in all dead nucleated cells. In addition, in cells containing both AO and PI, the green fluorescence is quenched and the cells still fluorescent red. With this, all live nucleated cells fluoresce green and all dead nucleated cells fluoresce red, allowing for clear distinction between viable and non-viable populations.

To perform the actual cell-count, $18 \mu \mathrm{l}$ of cell suspension were mixed with $2 \mu \mathrm{l}$ AO/PI dye. From this mixture, $10 \mu \mathrm{l}$ were pipetted on LUNA cell counting slides and measured in fluorescence modus with LUNA-FL.

To calculate the doubling times of the counted cells, the following formulas were used:

$n=\frac{\log (b / a)}{\log 2}$

$t=(h / n)$,

$a$ is the initial cells (seeded at the beginning of the experiment); $b$ is the end cells (counted at the end of the experiment, see Supplementary Fig. 2); $n$ is the number of doublings; $h$ is the hours in culture; $t$ is the doubling time.

\subsection{RNA extraction, reversed transcription and $\mathrm{qPCR}$ analysis}

RNA extraction from the treated cells was performed via NucleoSpin RNA-isolation kit (Macherey-Nagel, Germany) using the standard isolation protocol for adherent cells. The samples were stored at $-20^{\circ} \mathrm{C}$ until further use.

The concentration of RNA in the samples was determined via NanoDrop. For the reverse transcription, 500 ng RNA per sample were used. A master mix was prepared for the reverse transcription, containing $1 \mu \mathrm{l}$ random primer, $4 \mu \mathrm{l}$ $5 \times$ buffer, $1 \mu \mathrm{l}$ dNTPs (New England BioLabs), $1 \mu \mathrm{l}$ DTT and $2 \mu \mathrm{l}$ water per sample (Invitrogen Reverse Transcription Kit, Thermo Fisher Scientific, USA). Up to $10 \mu$ RNA were added to the mix and the rest of the volume up to $19 \mu \mathrm{l}$ was filled with water. The RNA was stretched for $10 \mathrm{~min}$ at $70{ }^{\circ} \mathrm{C}$. Afterwards $1 \mu \mathrm{l}$ Superscript enzyme (Invitrogen Reverse Transcription Kit, Thermo Fisher Scientific, USA) was added to each sample at room temperature followed by $45 \mathrm{~min}$ incubation at $42{ }^{\circ} \mathrm{C}$ and subsequently $10 \mathrm{~min}$ at $70{ }^{\circ} \mathrm{C}$. At the end of the reverse transcription, the sample were cooled and stored at $4{ }^{\circ} \mathrm{C}$.

For the qPCR analysis following each sample contained $10 \mu \mathrm{l}$ SybrGreen (Roche, Switzerland), $0.5 \mu \mathrm{l}$ forward primer, $0.5 \mu \mathrm{l}$ reverse primer, $8 \mu \mathrm{l}$ water and $1 \mu \mathrm{l}$ cDNA. For negative control $1 \mu \mathrm{l}$ water was used instead of cDNA. $20 \mu \mathrm{l}$ from each sample were pipetted in duplicates on a Roche 96-well LightCycler plate. Optimal annealing temperatures were determined for each gene of interest as shown in Table 1.

The LightCycler was programmed for 45 cycles of amplification. The end results were calculated with LightCycler 96 software and presented as ratio to housekeeper (b-Actin).

\subsection{DCFDA-ROS detection}

Cells were seeded on $10 \mathrm{~cm}$ dish at density $5 \times 10^{5}$ cells per dish in DMEM. The cells were cultured for 2 days at $37^{\circ} \mathrm{C}$. Afterwards the dishes were washed $1 \times$ with DMEM without FCS. From that point on, all remaining steps were performed in the dark. The cells were stained with $100 \mu \mathrm{M}$ DCFDA (Sigma-Aldrich, Germany), dissolved in DMEM without FCS. The staining was performed for $35 \mathrm{~min}$ at $37^{\circ} \mathrm{C}$ in the dark. Some cells were left unstained to be later used as background control. After the end of incubation, the cells were washed $2 \times$ with medium without FCS. They were thereafter trypsinized, counted and seeded on two black clear bottom 96 -well plates at density $1 \times 10^{4}$ cells per well in a total volume of $100 \mu \mathrm{l}$ per well. One plate was left as $0 \mathrm{~J} / \mathrm{cm}^{2}$ un-irradiated control and the other was immediately irradiated with a single dose of $18 \mathrm{~J} / \mathrm{cm}^{2}$ UVA1 to induce ROS (For irradiation protocol see Supplementary Fig. 2). After the irradiation, both plates were incubated for $30 \mathrm{~min}$

Table 1 Product size and annealing temperatures of the used primers (Sigma-Aldrich, Germany)

\begin{tabular}{llll}
\hline Gene of interest & Primer sequence: forward/reverse & $\begin{array}{l}\text { Size of prod- } \\
\text { uct }(\mathrm{bp})\end{array}$ & $\begin{array}{l}\text { Annealing } \\
\text { temperature } \\
\left({ }^{\circ} \mathrm{C}\right)\end{array}$ \\
\hline MMP1 & TCACCAAGGTCTCTGAGGGTCAAGC/ GGATGCCATCAATGTCATCCTGAGC & 324 & 65 \\
MMP2 & CCCCAAAACGGACAAAGAG/ CTTCAGCACAAACAGGTTGC & 88 & 51 \\
MMP3 & CAAAACATATTTCTTTGTAGAGAGGACAA/ TTCAGCTATTTGCTTGGGGAAA & 91 \\
MMP9 & GAACCAATCTCACCGACAGG/ GCCACCCGAGTGTAACCATA & 67 & 85 \\
MMP13 & CCAGTCTCCGAGGAGAAACA/ AAAAACAGCTCCGCCGCATCAAC & 85 & 57 \\
MMP15 & ACGGTCGTTTTGTCTTTTCA/ GTCAGCGGCTGTGGGTAG & 142 & 57 \\
TIMP1 & TGGATAAACAGGGAAACACTG/ GATGGACTCTTGCACATCAT & 54 \\
b-Actin & CTACGTCGCCCTGGACTTCGAGC/ GATGGAGCCGCCGATCCACACGG & 385 & $54-65$ \\
\hline
\end{tabular}


at $37{ }^{\circ} \mathrm{C}$ in the dark. Fluorescence was measured via Varioscan at Ex/Em $485 \mathrm{~nm} / 530 \mathrm{~nm}$.

For the evaluation of the measurements, the values for the unstained cells were subtracted from the DCFDA stained cells to exclude background noise.

The viability of the irradiated cells was performed $30 \mathrm{~min}$ after irradiation at the same time as the ROS measurement was performed (see Irradiation Protocol 2 in Supplementary Fig. 2).

\subsection{DNA extraction and detection of 8-0HdG as a sign of UVA1-induced DNA damage}

To retrieve DNA for subsequent 8-OHdG experiments, UVA1 treated cells ( 2 days and 4 days) and controls cultured on $20 \mathrm{~cm}$ petri dishes at seeding density of $8 \times 10^{5}$, were trypsinized, centrifuged and re-suspended in $200 \mu \mathrm{l} /$ sample PBS. From then on, a QUIamp Mini Kit (QIAGEN, Germany) was used for the isolation using standard kit protocol for adherent cells.

The method used to detect oxidative DNA damage in UVA1-irradiated cells was based on the OxiSelect ${ }^{\mathrm{TM}}$ ELISA Kit (Cell Biolabs Inc., USA). This kit is a competitive enzyme immunoassay for detection and quantitation of 8-OHdG in DNA samples. After performing staining according to the kit protocol, the absorbance the microwell plate was measured with a Varioscan Flash plate reader at $450 \mathrm{~nm}$.

For data analysis, the values from the standard were plotted in GraphPad Prism and the unknown values for the samples were extrapolated from the resulting curve.

\subsection{Comet assay}

In preparation for the comet assay, the cells were irradiated in accordance with the 4 days irradiation protocol described in point 5.2. Afterwards the cells were counted and resuspended at $1 \times 10^{5}$ cells $/ \mathrm{ml}$. Afterward, the comet assay was performed in accordance with Comet Assay protocol (Trevigen, USA) for Alkaline Comet Assay. SYBR-Gold was used for the subsequent DNA-staining and visualization. For the evaluation of the comets, the CometScore software Version 2.0.0.0 was used.

\subsection{Statistical analysis}

Data are shown as the mean with standard deviation of at least three independent experiments and statistical significance was tested with GraphPad Prism 8.3.1. (GraphPad Software, USA). Data were analysed with one-way ANOVA, coupled with Bonferroni's multiple comparison test. For significances: (ns) $P>0.05$; (*) $P<0.05$; (**) $P<0.005$; (***) $P<0.0005$; $(* * * *) P<0.0001)$. All data evaluated were acquired from three biological replicates.

\subsection{Heliovital Filter Foil specifications and measurements of the transmittance}

As shown in Fig. 1b, the HelioVital Filter Foil (HelioVital Filter LTL-3-130om (PP-PET-met.-multilayer-film) used in these experiments consists of multiple layers:

- Protective and weary layer-UV transparent polypropylene layer approved by food law (used to protect filter layer from external chemical or physical induced damages) (Fig. 1b layer 1 and 8);

- Adhesive layer-connecting layer (Fig. $1 \mathrm{~b}$ layer 2 and 7);

- Print layer-connecting layer (Fig. 1b layer 3),

- Metallization- - functional part contributing to the filter properties of foil (Fig. 1b layer 4);

- Filter layer-PET (Polyethyleneterephthalate) layer for pigmentation (functional part of filter properties of foil) (Fig. 1b layer 5);

- Pigmentation layer-functional part contributing to the filter properties of the foil (Fig. 1b layer 6).

The primary selective filtration of wavelengths in the UV range is achieved by the absorption behavior of the special polymers of the PET membrane and its thickness. This very thin PET membrane is also the substrate for the following secondary relative filtration layers by means of metallisation through vacuum sputtering and by means of printed pigment ducks, which are also partly components of the adhesives. The cover layers made of PP protect the entire modular film composite and thus enable practical handling and processing. The Filter foils had, following transmission in the UVR-range: UVB-25.3\%, UVA2 - 40.3\%, UVA1-41.9\%, (see Fig. 1a).

Measurements of the transmittance of the HelioVital filer foil (HelioVital Filter LTL-3-130om (PP-PET-Met.Multilayer-Film)) and glasses (Fig. 1 and Supplementary Fig. 3) were made in 1-nm increments using a high-precision dual-beam UV-VIS-NIR spectrophotometer of the type Cary 500 from Varian (now Agilent).

Supplementary Information The online version contains supplementary material available at https://doi.org/10.1007/s43630-022-00177-4.

Author contributions II, BK, KL, TM, MB and YK have substantially contributed to this study. YK, and MB planned the experiments. II and BK performed all experiments and analysed data with the help of YK and KL. II performed with the help of YK the graphic design. II, BK, YK, TM and MB wrote with the help of KL the manuscript, performed literature research, analyzed literature data and developed the hypothesis. II, BK, YK, KL, TM and MB approved the versions of the manuscript.

Funding Open Access funding enabled and organized by Projekt DEAL. This work was partially funded by HelioVital (HelioVital GmbH, Zollernring 32, 72186 Empfingen, Deutschland). 
Availability of data and materials Detailed information about used materials, methods and data are available upon request.

Code availability Not applicable.

\section{Declarations}

Conflicts of interest/competing interests The authors have no conflict of interest.

Open Access This article is licensed under a Creative Commons Attribution 4.0 International License, which permits use, sharing, adaptation, distribution and reproduction in any medium or format, as long as you give appropriate credit to the original author(s) and the source, provide a link to the Creative Commons licence, and indicate if changes were made. The images or other third party material in this article are included in the article's Creative Commons licence, unless indicated otherwise in a credit line to the material. If material is not included in the article's Creative Commons licence and your intended use is not permitted by statutory regulation or exceeds the permitted use, you will need to obtain permission directly from the copyright holder. To view a copy of this licence, visit http://creativecommons.org/licenses/by/4.0/.

\section{References}

1. Rai, R., Shanmuga, S. C., \& Srinivas, C. (2012). Update on photoprotection. Indian Journal of Dermatology, 57(5), 335-342. https://doi.org/10.4103/0019-5154.100472

2. Armstrong, B., Baverstock, K., Brenner, D., Cardis, E., Green, A., Guilmette, R., Hall, J., Hill, M., Hoel, D., Krewski, D., Little, M., Marshall, M., Mitchel, R., Muirhead, C., Priest, N., Richardson, D., Riddell, T., Sabatier, L., Sokolnikov, M., \& Ullrich, R. (2012). IARC monographs on the evaluation of carcinogenic risks to humans. Volume 100. A Review of Human Carcinogens. Part D: Radiation. 100. pp. 35-40

3. Rünger, T. M., Epe, B., \& Möller, K. (1995). Processing of directly and indirectly ultraviolet-induced DNA damage in human cells. Recent Results in Cancer Research, 139, 31-42. https://doi. org/10.1007/978-3-642-78771-3_3

4. Jaszewska, E., Soin, M., Filipek, A., \& Naruszewicz, M. (2013). UVA-induced ROS generation inhibition by Oenothera paradoxa defatted seeds extract and subsequent cell death in human dermal fibroblasts. Journal of Photochemistry and Photobiology B: Biology, 126, 42-46. https://doi.org/10.1016/j.jphotobiol.2013.07.001

5. Greinert, R., Volkmer, B., Henning, S., Breitbart, E. W., Greulich, K. O., Cardoso, M. C., \& Rapp, A. (2012). UVA-induced DNA double-strand breaks result from the repair of clustered oxidative DNA damages. Nucleic Acids Research, 40(20), 10263-10273. https://doi.org/10.1093/nar/gks824

6. D’Orazio, J., Jarrett, S., Amaro-Ortiz, A., \& Scott, T. (2013). UV radiation and the skin. International Journal of Molecular Sciences, 14(6), 12222-12248. https://doi.org/10.3390/ijms140612 222

7. Sage, E., Girard, P. M., \& Francesconi, S. (2012). Unravelling UVA-induced mutagenesis. Photochemical \& Photobiological Sciences, 11(1), 74-80. https://doi.org/10.1039/c1pp05219e

8. Vile, G. F., \& Tyrrell, R. M. (1995). UVA radiation-induced oxidative damage to lipids and proteins in vitro and in human skin fibroblasts is dependent on iron and singlet oxygen. Free Radical Biology and Medicine, 18(4), 721-730. https://doi.org/10.1016/ 0891-5849(94)00192-m
9. Dale Wilson, B., Moon, S., \& Armstrong, F. (2012). Comprehensive review of ultraviolet radiation and the current status on sunscreens. The Journal of Clinical and Aesthetic Dermatology, 5(9), 18-23.

10. Battie, C., Jitsukawa, S., Bernerd, F., Del Bino, S., Marionnet, C., \& Verschoore, M. (2014). New insights in photoaging, UVA induced damage and skin types. Experimental Dermatology, 23, 7-12. https://doi.org/10.1111/exd.12388

11. Noonan, F. P., Zaidi, M. R., Wolnicka-Glubisz, A., Anver, M. R., Bahn, J., Wielgus, A., Cadet, J., Douki, T., Mouret, S., Tucker, M. A., Popratiloff, A., Merlino, G., \& De Fabo, E. C. (2012). Melanoma induction by ultraviolet A but not ultraviolet $\mathrm{B}$ radiation requires melanin pigment. Nature Communications, 3, 884 . https://doi.org/10.1038/ncomms 1893

12. Jhappan, C., Noonan, F. P., \& Merlino, G. (2003). Ultraviolet radiation and cutaneous malignant melanoma. Oncogene, 22(20), 3099-3112. https://doi.org/10.1038/sj.onc. 1206450

13. Leiter, U., Eigentler, T., \& Garbe, C. (2014). Epidemiology of skin cancer. Advances in Experimental Medicine and Biology, 810, 120-140. https://doi.org/10.1007/978-1-4939-0437-2_7

14. Pittayapruek, P., Meephansan, J., Prapapan, O., Komine, M., \& Ohtsuki, M. (2016). Role of Matrix metalloproteinases in photoaging and photocarcinogenesis. International Journal of Molecular Sciences. https://doi.org/10.3390/ijms17060868

15. Hofmann, U. B., Eggert, A. A., Blass, K., Bröcker, E. B., \& Becker, J. C. (2005). Stromal cells as the major source for matrix metalloproteinase-2 in cutaneous melanoma. Archives for Dermatological Research. Archiv für Dermatologische Forschung, 297(4), 154-160. https://doi.org/10.1007/s00403-005-0588-2

16. Quintero-Fabián, S., Arreola, R., Becerril-Villanueva, E., TorresRomero, J. C., Arana-Argáez, V., Lara-Riegos, J., Ramírez-Camacho, M. A., \& Alvarez-Sánchez, M. E. (2019). Role of matrix metalloproteinases in angiogenesis and cancer. Frontiers in Oncology, 9, 1370. https://doi.org/10.3389/fonc.2019.01370

17. Deryugina, E. I., \& Quigley, J. P. (2006). Matrix metalloproteinases and tumor metastasis. Cancer and Metastasis Reviews, 25(1), 9-34. https://doi.org/10.1007/s10555-006-7886-9

18. Gonzalez-Avila, G., Sommer, B., Mendoza-Posada, D. A., Ramos, C., Garcia-Hernandez, A. A., \& Falfan-Valencia, R. (2019). Matrix metalloproteinases participation in the metastatic process and their diagnostic and therapeutic applications in cancer. Critical Reviews in Oncology/Hematology, 137, 57-83. https://doi.org/ 10.1016/j.critrevonc.2019.02.010

19. Saleeby, C. W. (1922). The advance of heliotherapy. Nature, 109(2742), 663-663. https://doi.org/10.1038/109663a0

20. Hölzle, E. (1997). Artificial Light Sources for Phototherapy. In P. Altmeyer, K. Hoffmann, \& M. Stücker (Eds.), Skin Cancer and UV Radiation. Berlin Heidelberg: Springer.

21. Autio, P., Komulainen, P., \& Larni, H. M. (2002). Heliotherapy in atopic dermatitis: A prospective study on climatotherapy using the SCORAD index. Acta Dermato-Venereologica, 82(6), 436-440. https://doi.org/10.1080/000155502762064575

22. Snellman, E., Lauharanta, J., Reunanen, A., Jansén, C. T., Jyrkinen-Pakkasvirta, T., Kallio, M., Luoma, J., Aromaa, A., \& Waal, J. (1993). Effect of heliotherapy on skin and joint symptoms in psoriasis: A 6-month follow-up study. British Journal of Dermatology, 128(2), 172-177. https://doi.org/10.1111/j.1365-2133. 1993.tb15147.x

23. Choukroun, J., \& Geoffroy, P. A. (2019). Light therapy in mood disorders: A brief history with physiological insights. Chronobiol Med, 1(1), 3-8. https://doi.org/10.33069/cim.2018.0009

24. van Praag, M. C., Tseng, L. N., Mommaas, A. M., Boom, B. W., \& Vermeer, B. J. (1993). Minimising the risks of PUVA treatment. Drug Safety, 8(5), 340-349. https://doi.org/10.2165/00002 018-199308050-00002 
25. Paul, C. F., Ho, V. C., McGeown, C., Christophers, E., Schmidtmann, B., Guillaume, J.-C., Lamarque, V., \& Dubertret, L. (2003). Risk of malignancies in psoriasis patients treated with cyclosporine: a 5 y cohort study. Journal of Investigative Dermatology, 120(2), 211-216. https://doi.org/10.1046/j.1523-1747.2003. 12040.x

26. Guo, Z., Okamoto, H., Danno, K., \& Imamura, S. (1992). The effects of non-interval PUVA treatment on Langerhans cells and contact hypersensitivity. Journal of Dermatological Science, 3(2), 91-96. https://doi.org/10.1016/0923-1811(92)90041-9

27. McKenna, K. E. (1997). PUVA, Psoralens and Skin Cancer. In P. Altmeyer, K. Hoffmann, \& M. Stücker (Eds.), Skin Cancer and UV Radiation. Berlin Heidelberg: Springer.

28. Morton, C. A., Szeimies, R.-M., Sidoroff, A., \& Braathen, L. R. (2013). European guidelines for topical photodynamic therapy part 1: treatment delivery and current indications - actinic keratoses. Bowen's disease, basal cell carcinoma, Journal of the European Academy of Dermatology and Venereology, 27(5), 536-544. https://doi.org/10.1111/jdv.12031

29. De Berker, D., McGregor, J. M., Hughes, B. R., Guidelines, o.b.o.t.B.A.o.D.T., and Subcommittee, A. (2007). Guidelines for the management of actinic keratoses. British Journal of Dermatology, 156(2), 222-230. https://doi.org/10.1111/j.1365-2133.2006. 07692.x

30. Christensen, E., Warloe, T., Kroon, S., Funk, J., Helsing, P., Soler, A., Stang, H., Vatne, Ø., \& Mørk, C. (2010). Guidelines for practical use of MAL-PDT in non-melanoma skin cancer. Journal of the European Academy of Dermatology and Venereology, 24(5), 505-512. https://doi.org/10.1111/j.1468-3083.2009.03430.x

31. Wiegell, S. R., Fabricius, S., Stender, I. M., Berne, B., Kroon, S., Andersen, B. L., Mørk, C., Sandberg, C., Jemec, G. B. E., Mogensen, M., Brocks, K. M., Philipsen, P. A., Heydenreich, J., Hædersdal, M., \& Wulf, H. C. (2011). A randomized, multicentre study of directed daylight exposure times of $1 \frac{1}{2}$ vs. $2^{1 / 2} \mathrm{~h}$ in daylight-mediated photodynamic therapy with methyl aminolaevulinate in patients with multiple thin actinic keratoses of the face and scalp. British Journal of Dermatology, 164(5), 1083-1090. https://doi.org/10.1111/j.1365-2133.2011.10209.x

32. Wiegell, S. R., Fabricius, S., Gniadecka, M., Stender, I. M., Berne, B., Kroon, S., Andersen, B. L., Mørk, C., Sandberg, C., Ibler, K. S., Jemec, G. B. E., Brocks, K. M., Philipsen, P. A., Heydenreich, J., Hædersdal, M., \& Wulf, H. C. (2012). Daylight-mediated photodynamic therapy of moderate to thick actinic keratoses of the face and scalp: a randomized multicentre study. British Journal of Dermatology, 166(6), 1327-1332. https://doi.org/10.1111/j.13652133.2012.10833.x

33. Matuszko, D. (2012). Influence of the extent and genera of cloud cover on solar radiation intensity. International Journal of Climatology, 32(15), 2403-2414. https://doi.org/10.1002/joc.2432

34. Latha, M. S., Martis, J., Shobha, V., Sham Shinde, R., Bangera, S., Krishnankutty, B., Bellary, S., Varughese, S., Rao, P., \& Naveen Kumar, B. R. (2013). Sunscreening agents: A review. Journal of Clinical and Aesthetic Dermatology, 6(1), 16-26.

35. Duarte, I., Rotter, A., Malvestiti, A., \& Silva, M. (2009). The role of glass as a barrier against the transmission of ultraviolet radiation: An experimental study. Photodermatology, Photoimmunology and Photomedicine, 25(4), 181-184. https://doi.org/10.1111/j. 1600-0781.2009.00434.X

36. Gabros, S., Nessel, T. A., \& Zito, P. M. (2021). Sunscreens and photoprotection. StatPearls. StatPearls PublishingCopyright () 2021, StatPearls Publishing LLC.

37. Berneburg, M., Grether-Beck, S., Kurten, V., Ruzicka, T., Briviba, K., Sies, H., \& Krutmann, J. (1999). Singlet oxygen mediates the UVA-induced generation of the photoaging-associated mitochondrial common deletion. Journal of Biological Chemistry, 274(22), 15345-15349.
38. Pu, X., Wang, Z., \& Klaunig, J. E. (2015). Alkaline comet assay for assessing DNA damage in individual cells. Current Protocols in Toxicology, 65, 3.12.1-3.12.11. https://doi.org/10.1002/04711 40856.tx0312s65

39. Agar, N. S., Halliday, G. M., Barnetson, R. S., Ananthaswamy, H. N., Wheeler, M., \& Jones, A. M. (2004). The basal layer in human squamous tumors harbors more UVA than UVB fingerprint mutations: A role for UVA in human skin carcinogenesis. Proceedings of the National Academy of Sciences U S A, 101(14), 4954-4959. https://doi.org/10.1073/pnas.0401141101

40. Bachelor, M. A., \& Bowden, G. T. (2004). UVA-mediated activation of signaling pathways involved in skin tumor promotion and progression. Seminars in Cancer Biology, 14(2), 131-138. https:// doi.org/10.1016/j.semcancer.2003.09.017

41. Gendron, P. S., \& Rochette, P. (2015). Modifications in stromal extracellular matrix of aged corneas can be induced by ultraviolet A irradiation. Aging Cell. https://doi.org/10.1111/acel.12324

42. Herrmann, G., Wlaschek, M., Lange, T. S., Prenzel, K., Goerz, G., \& Scharffetter-Kochanek, K. (1993). UVA irradiation stimulates the synthesis of various matrix-metalloproteinases (MMPs) in cultured human fibroblasts. Experimental Dermatology, 2(2), 92-97. https://doi.org/10.1111/j.1600-0625.1993.tb00015.x

43. Naru, E., Suzuki, T., Moriyama, M., Inomata, K., Hayashi, A., Arakane, K., \& Kaji, K. (2005). Functional changes induced by chronic UVA irradiation to cultured human dermal fibroblasts. British Journal of Dermatology, 153(Suppl 2), 6-12. https://doi. org/10.1111/j.1365-2133.2005.06964.x

44. Catalgol, B., Ziaja, I., Breusing, N., Jung, T., Höhn, A., Alpertunga, B., Schroeder, P., Chondrogianni, N., Gonos, E. S., Petropoulos, I., Friguet, B., Klotz, L.-O., Krutmann, J., \& Grune, T. (2009). The proteasome is an integral part of solar ultraviolet a radiation-induced gene expression. Journal of Biological Chemistry, 284(44), 30076-30086. https://doi.org/10.1074/jbc.M109. 044503

45. Overall, C. M., Wrana, J. L., \& Sodek, J. (1991). Transcriptional and post-transcriptional regulation of $72-\mathrm{kDa}$ gelatinase/type IV collagenase by transforming growth factor-beta 1 in human fibroblasts. Comparisons with collagenase and tissue inhibitor of matrix metalloproteinase gene expression. Journal of Biological Chemistry, 266(21), 14064-14071.

46. Berry, R., \& López-Martínez, G. (2020). A dose of experimental hormesis: When mild stress protects and improves animal performance. Comparative Biochemistry and Physiology Part A: Molecular \& Integrative Physiology, 242, 110658. https://doi. org/10.1016/j.cbpa.2020.110658

47. Schirrmacher, V. (2021). Less can be more: The Hormesis theory of stress adaptation in the global biosphere and its implications. Biomedicines, 9(3), 293.

48. Ristow, M., \& Schmeisser, K. (2014). Mitohormesis: Promoting health and lifespan by increased levels of reactive oxygen species (ROS). Dose-Response A: Publication of International Hormesis Society, 12(2), 288-341. https://doi.org/10.2203/dose-response. 13-035.Ristow

49. Shibamoto, Y., \& Nakamura, H. (2018). Overview of biological, epidemiological, and clinical evidence of radiation hormesis. International Journal of Molecular Sciences. https://doi.org/10. 3390/ijms 19082387

50. Mattson, M. P. (2008). Hormesis defined. Ageing Research Reviews, 7(1), 1-7. https://doi.org/10.1016/j.arr.2007.08.007

51. Plauth, A., Geikowski, A., Cichon, S., Wowro, S. J., Liedgens, L., Rousseau, M., Weidner, C., Fuhr, L., Kliem, M., Jenkins, G., Lotito, S., Wainwright, L. J., \& Sauer, S. (2016). Hormetic shifting of redox environment by pro-oxidative resveratrol protects cells against stress. Free Radical Biology and Medicine, 99, 608-622. https://doi.org/10.1016/j.freeradbiomed.2016.08.006 